Acta vet. scand. $1973,14,392-409$.

From the Institute for Experimental Pathology, University of Iceland, Keldur, Reykjavík.

\title{
CARCINOMA OF THE SMALL INTESTINE OF SHEEP IN ICELAND
}

\section{A PATHOLOGICAL AND EPIZOOTIOLOGICAL STUDY}

\author{
By
}

G. Georgsson and H. Vigfússon

GEORGSSON, G. and H. VIGFÚSSON: Carcinoma of the small intestine of sheep in Iceland. A pathological and epizootiological study. Acta vet. scand. 1973, 14, 392-409. - This paper deals with an unusually high incidence, i.e. $0.97 \%$ of carcinoma of the small intestine found in Icelandic sheep. The tumours were situated in the jejunum and upper ileum. The macroscopic and microscopic pathology is described and compared with carcinoma of the small intestine of domestic animals and humans.

Aetiological factors are discussed and the possibility of exposure to carcinogenic substances, especially nitrosamines in food concentrates, is suggested.

Finally these findings are discussed in relation to current ideas on carcinogenesis in the intestines.

carcinoma; small intestine; sheep; pathology; epizootiology.

During surveys to detect paratuberculosis among sheep in Iceland an obstructive lesion of the small intestine was frequently observed. Adult sheep were most commonly affected, whereas young sheep were seldom affected and lambs never. The clinical symptoms were unthriftiness, gradual loss of weight and distension of the abdomen. The disease progressed slowly and proved invariably fatal after a few months' course. The gross post-mortem findings were different from those of paratuberculosis as first pointed out by Gislason (unpublished), who considered it a neoplastic process. At that time, however, histological examination to confirm the diagnosis was not conclusive. 


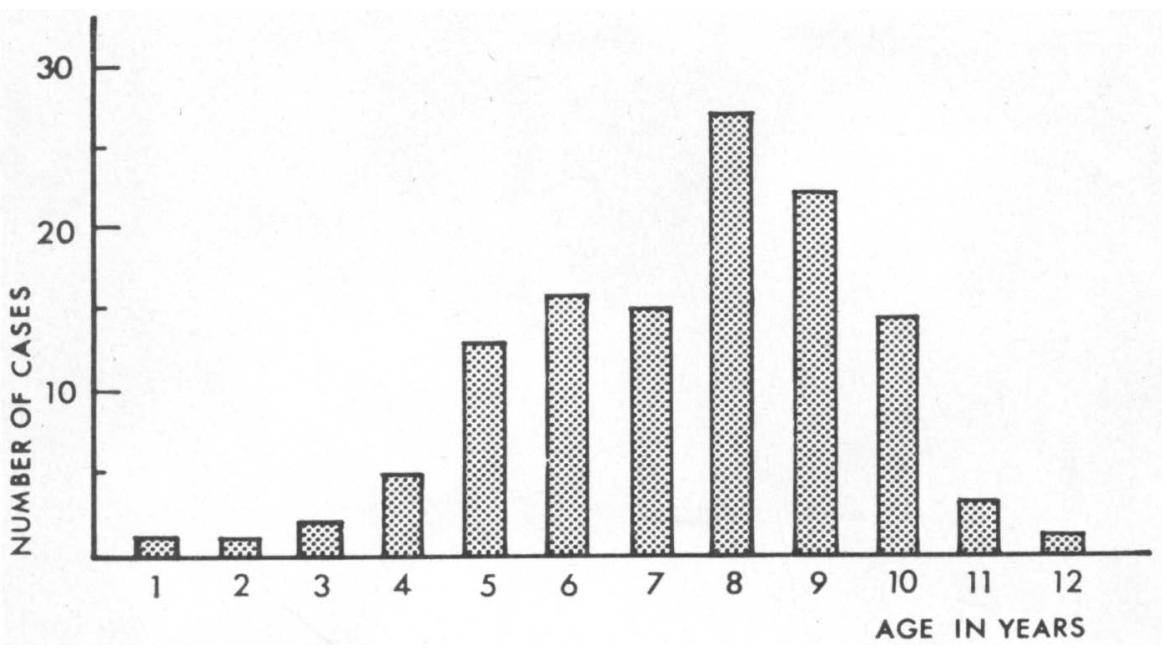

Figure 1. Histogram showing the age distribution of sheep with carcinoma of the small intestine.

As tumours of the small intestine are very rare both in man and animals, a histopathological study of this disease was undertaken to ascertain its nature, and data on its frequency were collected.

\section{MATERIAL AND METHODS}

Slaughtering of sheep in the autumn 1968 was surveyed at an abattoir in Borgarnes in the southwestern part of Iceland. All tumours of the small intestine were collected and examined grossly. Eleven of the tumours found at this survey were submitted to histological study. Nine well preserved cases necropsied at our institute during the last two years were also examined histologically, making a total of 20 cases for histological examination.

The tissue was fixed in $\mathbf{1 0} \%$ formol and embedded in paraffin. Sections were cut at $5 \mu$ and stained with haematoxylin-eosin, Masson's trichrome or Goldner's modification of this stain for connective tissue, periodic acid-Schiff reaction for mucopolysaccharides, alcian blue or alcian green at $\mathrm{pH} 2.6$ for acid mucopolysaccharides, and with a modification of alcian blue for hyaluronic acid (Pearse 1968). In seven cases the Masson-Fontana method for argentaffin cells was also applied. 


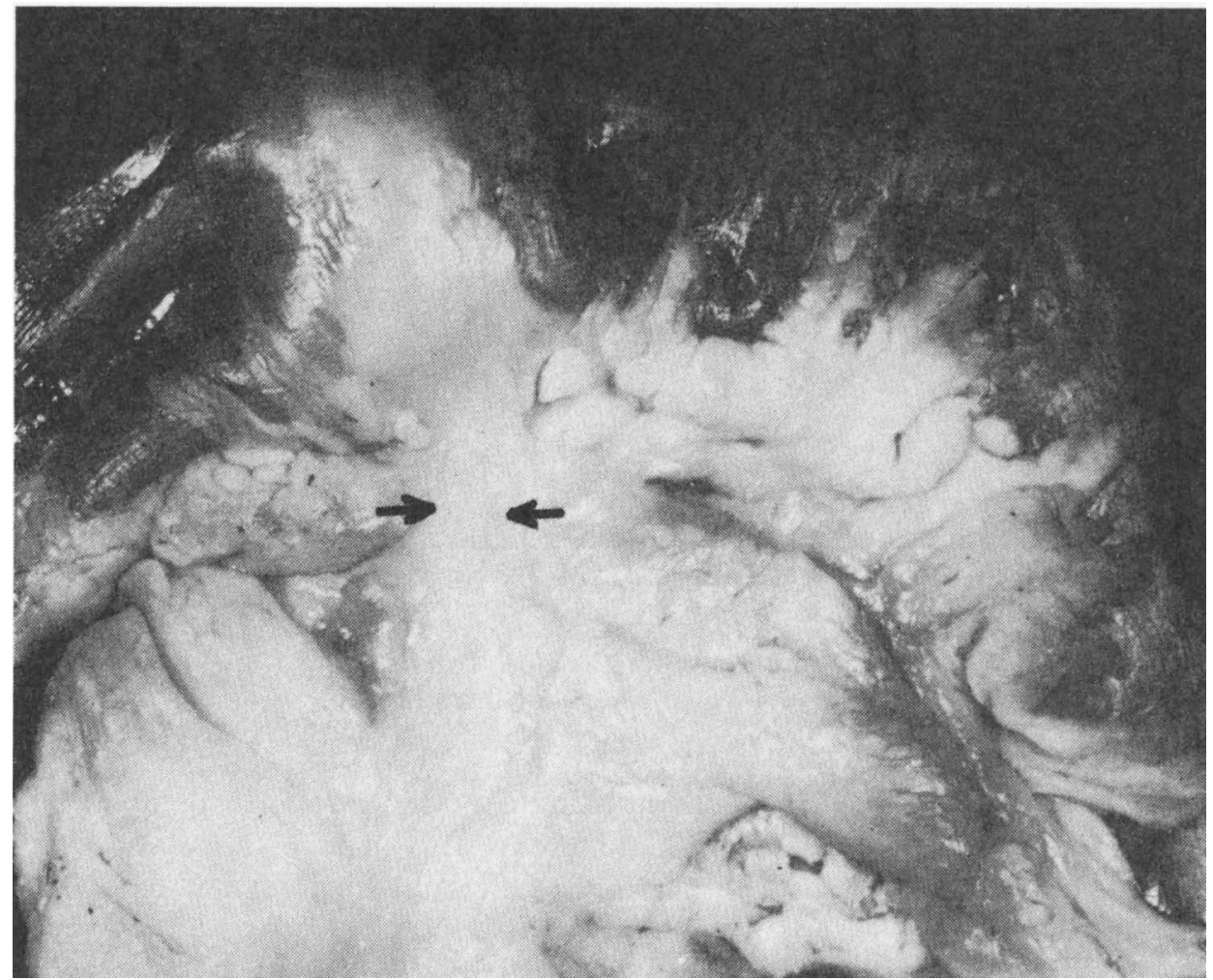

Fig u r e 2. External view of the primary tumour. Note the extension of the tumour into the mesentery (arrows).

As reliable information on the age of the affected sheep was only available in few of our cases, we looked through the records on tumours of the small intestine of sheep found in specimens submitted to our institute for diagnostic purposes in the years $1940-1970$ for further data on the age of affected sheep.

\section{RESULTS}

The slaughtering of 6470 sheep, one year old or more, was surveyed. Tumours of the small intestine were found in 63 sheep, corresponding to an incidence of $0.97 \%$.

In 118 cases information on the age of affected sheep was obtained, mainly from the records of the institute. Fig. 1 shows the age distribution of affected sheep. The youngest affected sheep was a yearling. The number of cases rises distinctly at the 


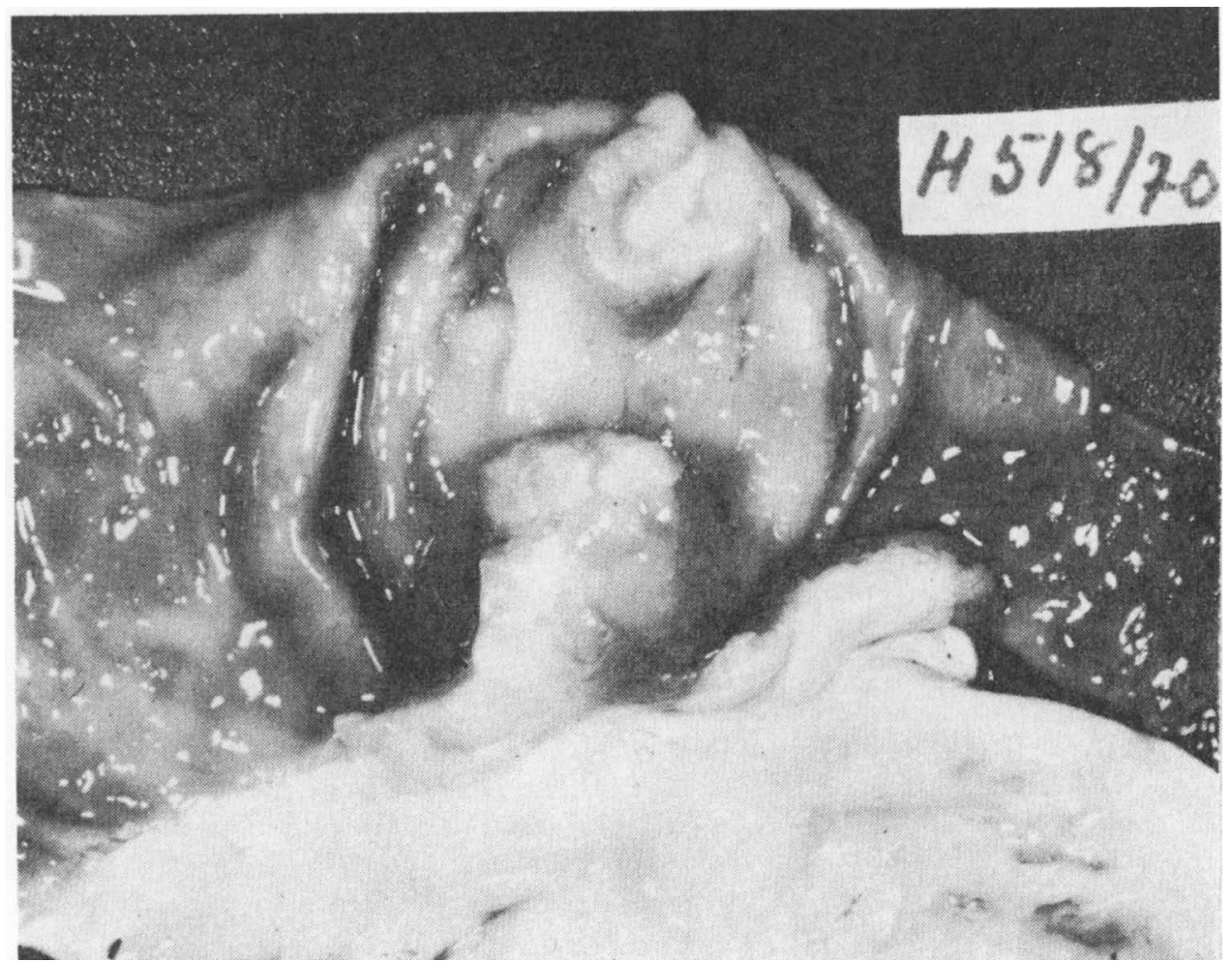

Fig u re 3. Cut surface of the tumour. The mucosa is thickened but intact. The stenosis of the gut is mainly caused by scirrhous spread of the tumour in the serosa. Note the dilation of the gut proximal to the tumour.

age of five years, only nine cases being found in younger sheep, and reaches a maximum at eight years. The average age of the whole group was 7.5 years.

\section{Gross pathology}

In most cases we found straw-coloured, clear fluid in the peritoneal cavity. The volume of the ascitic fluid was usually a few litre, but in one case $20 \mathrm{l}$ were measured. The site of the primary tumour was in all cases the middle or lower part of the small intestine. The typical appearance was that of a dense whitish cord, encircling and constricting the gut (Fig. 2). The cord varied from $1 / 2$ to 2 or $3 \mathrm{~cm}$ in width and $1 / 2$ to $2 \mathrm{~cm}$ in thickness. In 


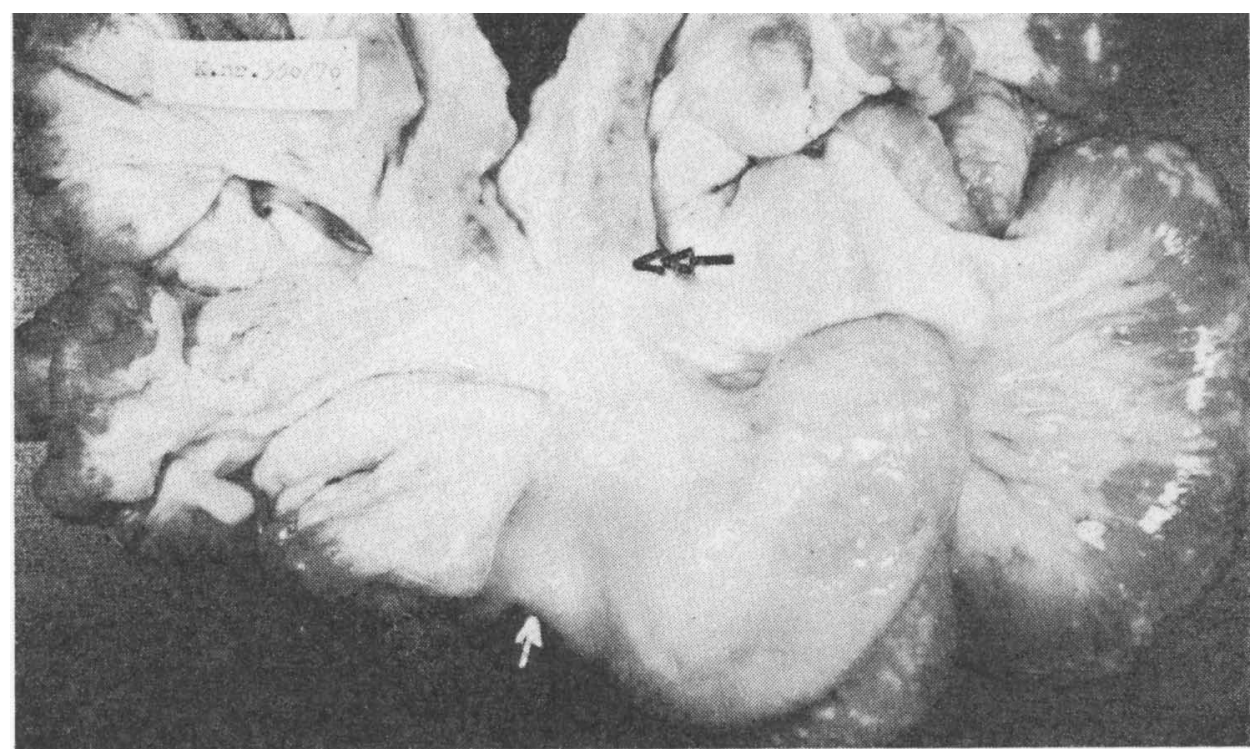

Fig u re 4. Small intestine with primary tumour at the arrow. Extension of the tumour across the mesentery to the mesenterial lymph nodes (double arrow). Note the dissemination of the tumour in the serosa proximal to the primary tumour.

early cases the cord did not completely encircle the gut, whereas in far advanced cases with widespread peritoneal dissemination two or three such constrictions werc occasionally noted. In all cases a thin cord of similar appearance invaded the mesentery, usually extending across the mesentery to the regional lymph nodes (Fig. 4). On opening the gut stenosis of the lumen corresponding to the external cord was seen (Figs. 3 and 5 ). In far advanced cases the lumen of the gut was practically occluded. By gross examination the mucosa at the site of the primary tumour seemed generally intact. There was only slight, diffuse thickening of the mucosa without well defined tumour mass (Fig. 3). The mucosal relief was somewhat coarser than normal and rarely ulcerated. The stenosis of the gut was mainly caused by the dense cord of tumour encircling and constricting the gut and to some extent by hypertrophy of the muscular layers of the bowel wall. In some cases slender polyps projected from the stenotic part into the gut. The polyps were blue-reddish, the surface smooth and glistening (Fig. 6). Superficial necrosis and ulceration were occasionally observed. The gut was dilated proxi- 


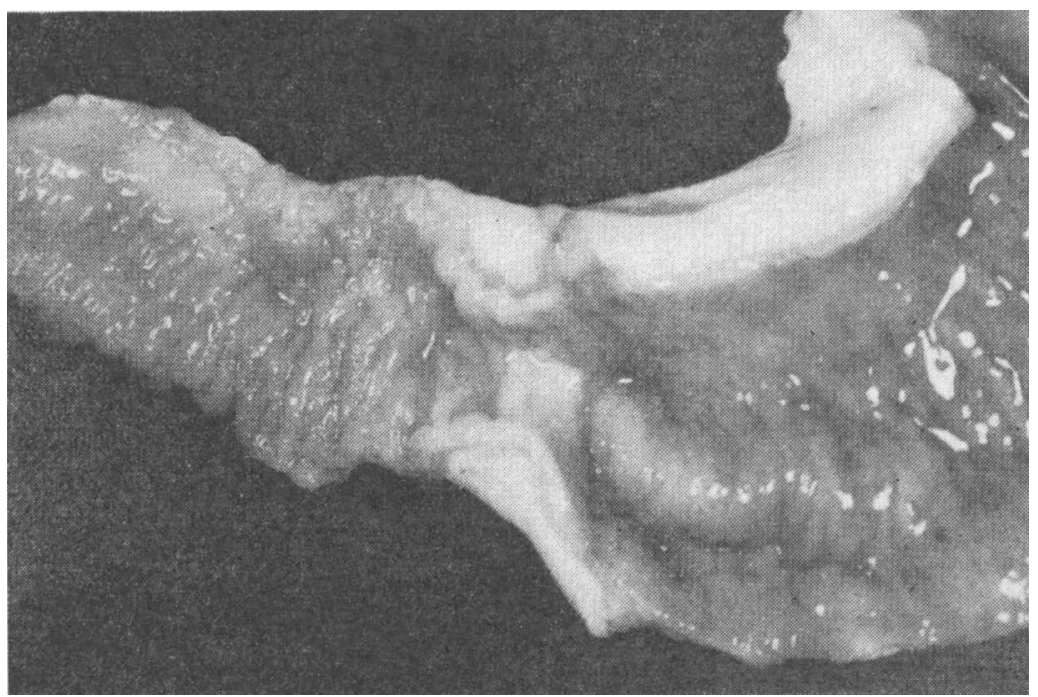

Figure 5. Same as Fig. 4, cut surface. Thick sheet of scirrhous tumour in the serosa proximal to the primary tumour. The mucosa is intact and the well preserved but distinctly hypertrophic muscular layer can be seen at the site of the primary tumour.

mal to the stenosis, but collapsed distally. The mucosa of the adjacent proximal segment was often hyperaemic and thickened.

In most cases the tumour had spread to the peritoneum. The peritoneal dissemination appeared as white spots or plaques, and sometimes formed confluent sheets of white dense tissue, up to $1 / 2-1 \mathrm{~cm}$ in thickness (Figs. 4 and 5 ). In one case the peritoneal infiltrates of the tumour were villous, grey-reddish and soft to the touch. The peritoneal spread was usually confined to the serosa and mesenterial attachment of a 1/2-1 m long segment of the gut proximal to the primary tumour. The distal boundary of the peritoneal spread was usually remarkably sharp, coinciding with the distal margin of the primary tumour (Fig. 4). In two cases extensive peritoneal dissemination was observed in the mesentary, greater omentum, the diaphragm, the serosa of the small intestine and the stomach and forestomachs, and the capsule of the liver and the spleen. In these two cases the tumour had penetrated through the diaphragm to the pleural cavities, leading to bilateral hydrothorax. In one of the cases invasion of the pericardial sac was also present with concomitant hydro- 


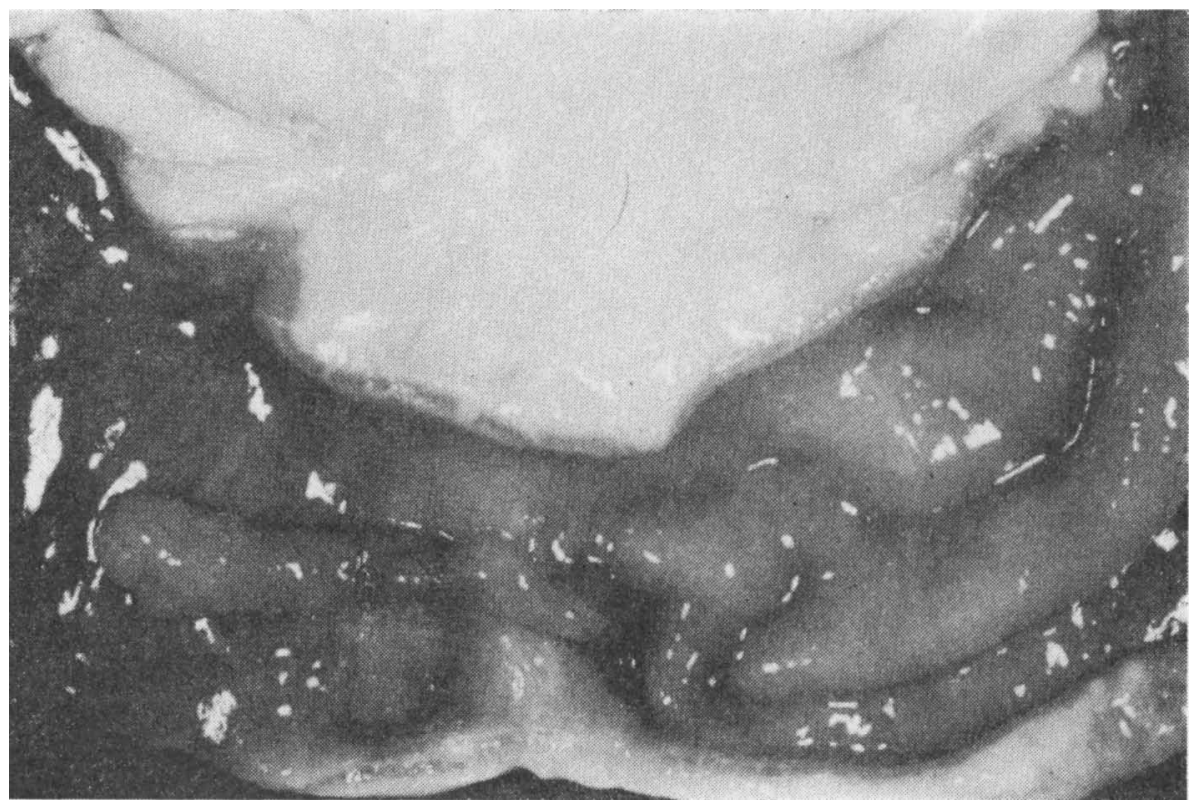

F ig u r e 6. Slender polyp covered by intact mucosa projecting into the lumen from the stenotic part of the gut.

pericardium. In this case metastases were found in mediastinal lymph nodes.

Metastases were always found in the mesenterial lymph nodes, whereas haematogenous metastases were only seen in one case, as multiple small tumour nodules in the liver. In this case metastases were found in lymph nodes at the cranial border of the pancreas, in the liver hilus as well as in the mesenterial lymph nodes, but peritoneal spread was not observed.

\section{Histopathology}

Histological examination of the tumours revealed carcinomas of essentially similar structure in the majority of cases. The cellular pattern was generally that of solid sheets of densely packed tumour cells, sometimes with trabecular arrangement (Fig. 7), occasionally displaying groups of irregular gland formations. In few cases a glandular pattern predominated (Fig. 8). This was especially prominent in the case with haematogenous metastasis. In some of the undifferentiated tumours glandular organization 


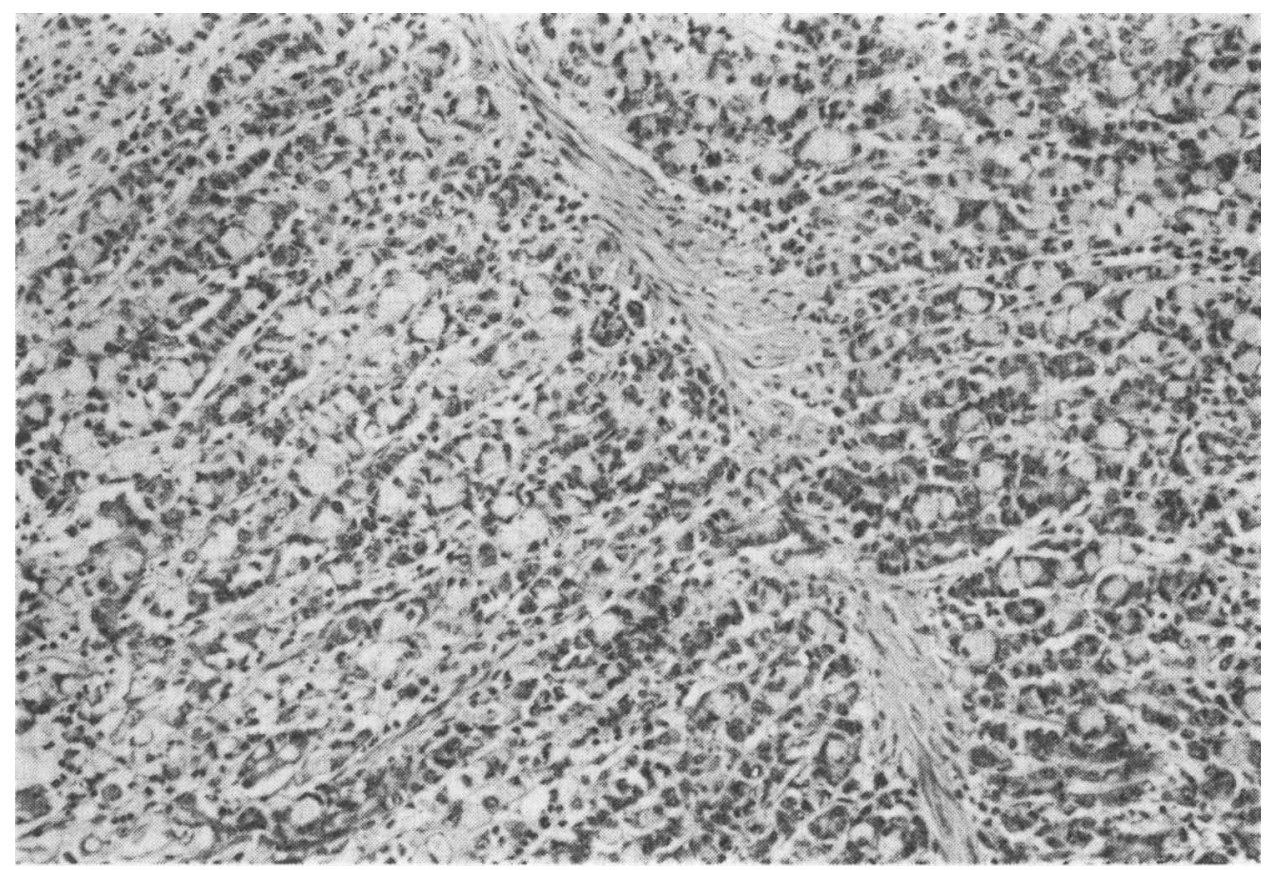

Fig u re 7. Histologic section of a cellular tumour, composed of solid closely packed cords of tumour cells. Muscularis mucosae is remarkably well preserved. Submucosa is to the right. H. \& E. $\times 160$.

became evident in the lymph node metastasis. The tumour cells were cuboidal or columnar when organized in glandular formations, but round or polygonal with pleomorphic nuclei in the anaplastic parts of the tumours. Mitoses were numerous. Mucus secretion was observed in all tumours but of varying degree. Sometimes it was very pronounced with numerous signet ring cells (Fig. 9 a) and glands distended with mucus (Fig. 9 b). The mucus was PAS positive and showed similar staining pattern although with weaker reaction with the alcian blue and alcian green methods.

In the mucosa the tumours were cellular with sparse fibrous stroma, except in some of the polyps. A more pronounced but still moderate stromal response was noted in the submucosa, whereas an intense desmoplastic reaction was found, where the tumours spread within the serosa, the mesentery and the peritoneum. The tumour was definitely scirrhous in these localizations with scattered small groups and cords of tumour cells and occasional 


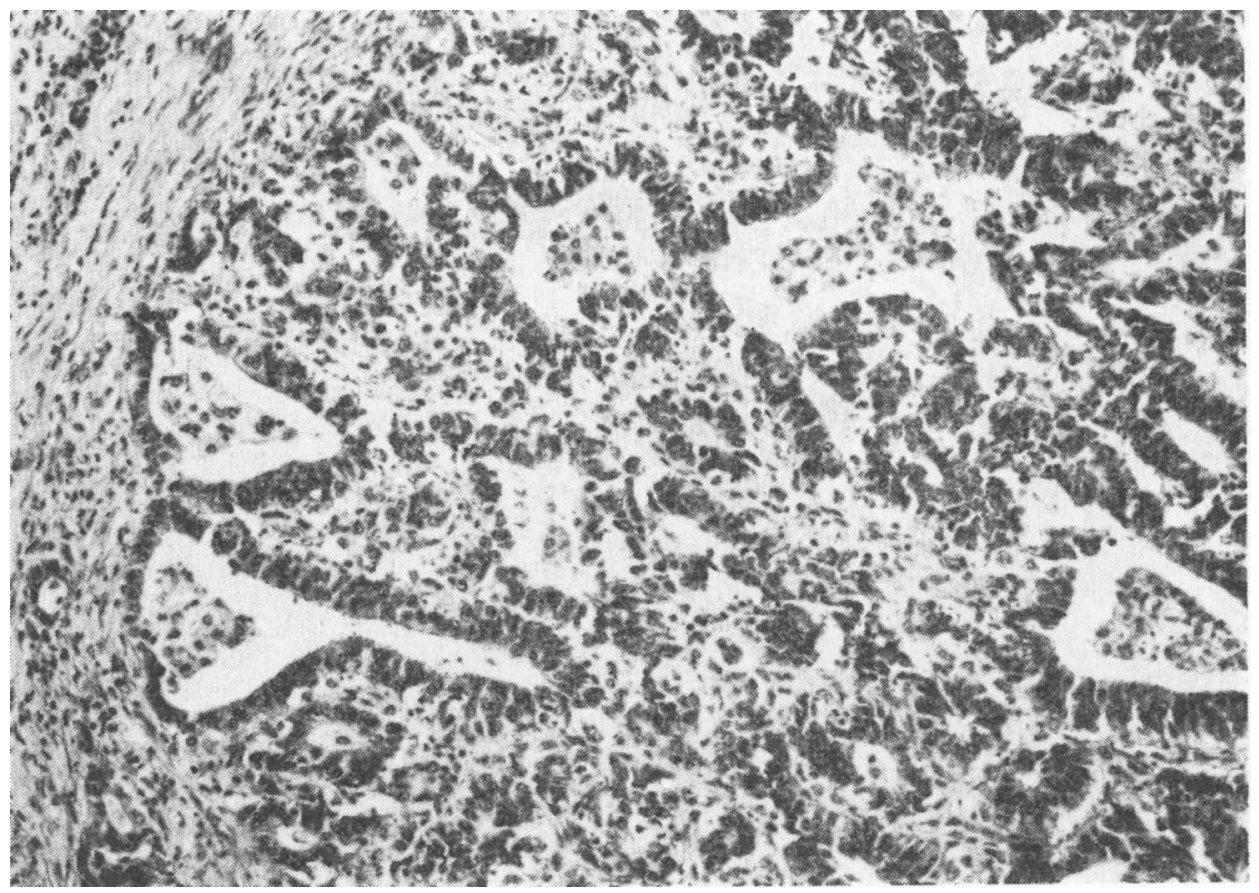

F i g u r e 8. Histologic section of a tumour, where irregular gland formations predominate. H. \& E. $\times 160$.

gland formations in dense collagenous stroma (Fig. 9 c). Calcification and metaplastic bone formation was found in the stroma of some tumours.

The tumour originated and spread generally in the basal layer of the mucosa causing moderate thickening of this layer. Invasion into the submucosa often with more extensive peripheral spread than in the mucosa was usually observed. The tumours had always penetrated the distinctly hypertrophic muscular coat and spread into the serosa, which was greatly thickened in all cases. Rarely small superficial necroses with accompanying acute inflammatory reaction were present at the luminal border of the tumour and on the surface of polyps. The tumour, although infiltrating widely, exhibited little tendency to tissue destruction. Muscularis mucosae and the muscular coat of the bowel wall were remarkably well preserved in spite of wide infiltration in the submucosa and serosa (Fig. 7). 

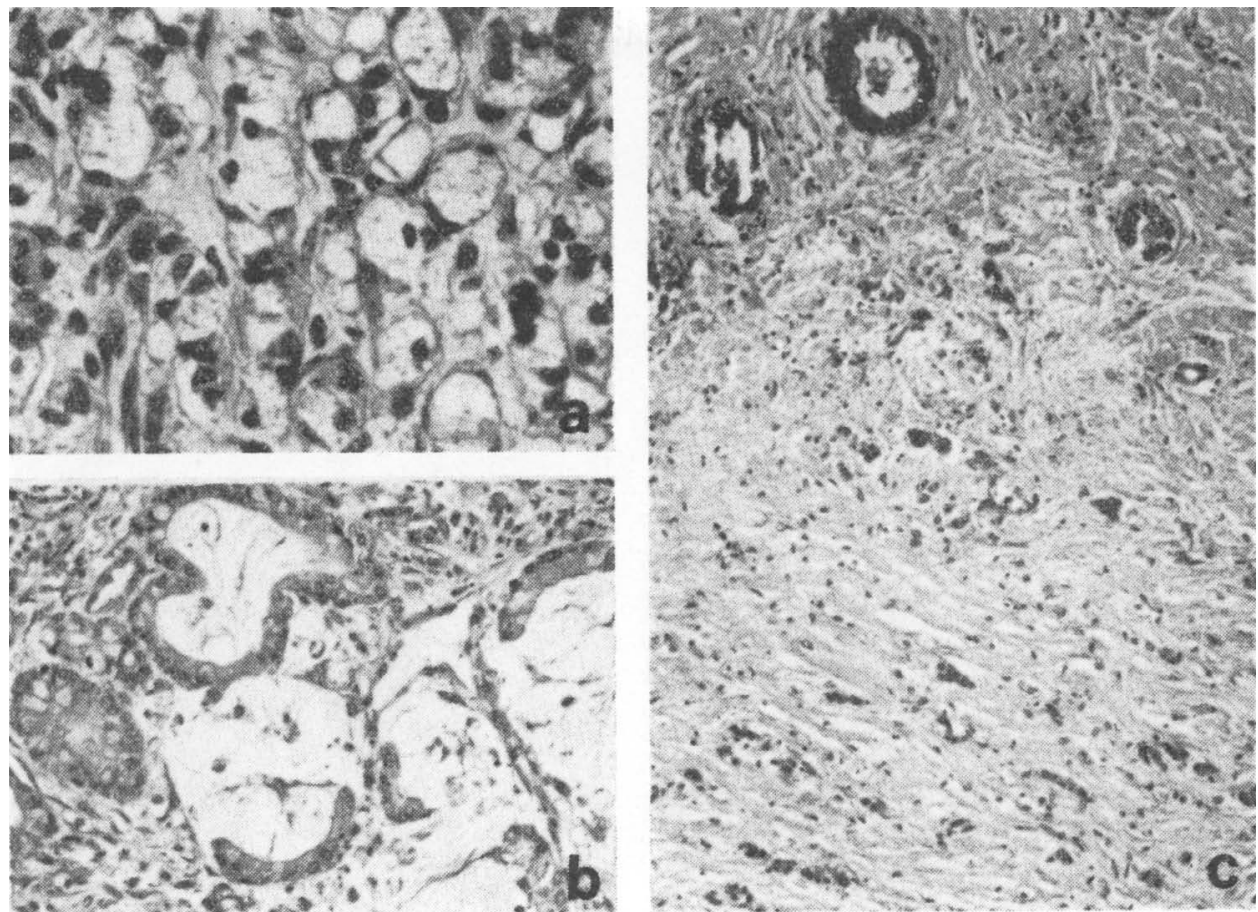

Figu re 9 a. From a tumour with closely packed signet ring cells. H. \& E. $\times 400$.

b. Tumour with irregular gland formations distended with mucus. H. \& E. $\times 160$.

c. Prominent desmoplasia in tumour spreading in the serosa. H. \& E. $\times 160$.

Tumour invasion into lymphatic vessels was frequently seen, whereas blood vessel invasion was not found. In the mesentery continuous spread of the tumour from the gut to regional mesenterial lymph nodes was observed. The tumour permeated in and along lymphatic vessels and along nerve sheaths and blood vessels. It was confined to the adventitia of arteries, but of ten infiltrating the media of veins without breaking through the internal elastic lamina.

The serosal lining over the tumour plaques was always intact. The mesothelial cells were generally of normal appearance. Occasionally, the mesothelial cells were round or cuboidal and sometimes multilayered, but an indication of malignant transformation of these cells was not found. 

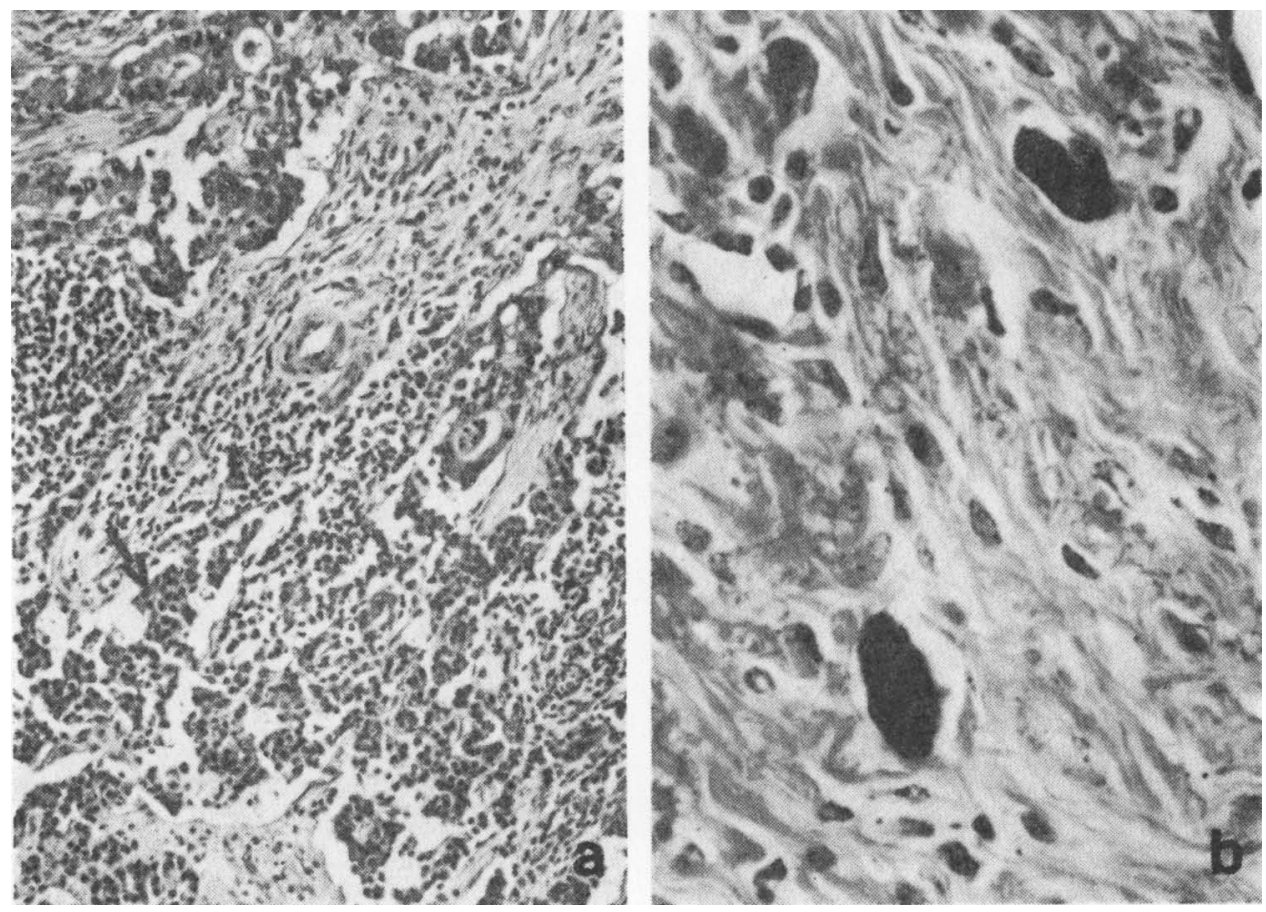

F i g u r e 10 a. Metastasis in mesenterial lymph node with admixture of solid cords of small uniform cells (arrow). H. \& E. $\times 160$.

b. Argentaffin cells in tumour infiltrating the serosa. Masson-Fontana. $\times 640$.

An admixture of a different cell type was noted in lymph node metastases of two cases. These cells were small, with a round and darkly staining nucleus surrounded by a thin rim of cytoplasm. They were uniform and grew in solid cords (Fig. 10 a). Some of them were positive with the Masson-Fontana method for enterochromaffin cells. This method was applied to further five cases. In all of them scattered argentaffin cells were demonstrated (Fig. $10 \mathrm{~b}$ ), both in the primary tumour and tumour infiltrates.

\section{DISCUSSION}

According to the results of the pathological study this obstructive lesion of the small bowel of sheep is a carcinoma arising from the mucosa of jejunum and upper ileum. The incidence of $0.97 \%$ found in our survey is unusually high both in comparison 
with the incidence in domestic animals (Cotchin 1956, Monlux et al. 1956 and Moulton 1961) and humans (McPeak 1967). The only exception are reports on small intestinal carcinoma of sheep in New Zealand. Dodd (1960) reported 25 cases of carcinoma of the small intestine in sheep, an incidence of $0.5 \%$ in sheep necropsied at the Ruakura Animal Health Laboratory. Webster (1967) found a similar incidence at an abattoir survey, i.e. $0.52 \%$ in sheep five-seven years old. The overall incidence in sheep one year old or more was $0.25 \%$ or about one fourth of the incidence found in our survey of sheep in the same age group. As in our series, sheep five years old or more were mainly affected, although Webster (1967) found as we did an occasional tumour in younger sheep, even yearlings. Cordes \& Shortridge (1971) found a similar age distribution of carcinoma of the small intestine of sheep observed at the Ruakura Animal Health Laboratory from 1956 to 1968 . They collected 143 cases in this period and of 61 cases, where the approximate age was known, only four were found in sheep younger than five years. In Australia McDonald \& Leaver (1965) observed a limited outbreak of carcinoma of the small intestine of sheep on one property for a five year period. The annual incidence during this time was $0.4 \%$ of all sheep and $2 \%$ of sheep over five years of age.

The localization of the tumour in our material in the lower part of jejunum and upper part of ileum corresponds with the findings of Dodd and Webster (1966), who found the tumour exclusively in the middle or lower third of the small intestine. This differs markedly from the localization of the small intestinal carcinoma in man, where $48 \%$ are found in duodenum (Wood 1967). Cordes \& Shortridge found seven cases in the duodenum out of 60 cases with known localization.

The macroscopic features of the tumour in our cases resemble closely the description by Webster (1966) and Cordes \& Shortridge (1971), and the main features are similar to those observed by Dodd. These authors describe the primary tumour as annular constrictive growth, which corresponds to our findings. This is comparable with the "napkin ring" configuration commonly observed in carcinoma of jejunum and ileum in man (Evans 1966 and Wood). Occasionally we found one or two separate constrictions of the gut proximal to the primary tumour. This was only observed in cases with widespread peritoneal dissemination and was caused by circular spread of the tumour in the serosa. We 
did not find indication for multiple primary tumours as suggested by Dodd in one of his cases with two separate annular constrictions of the gut.

As in our cases Dodd, Webster (1966) and Cordes \& Shortridge (1971) usually found that the tumour had spread beyond the intestinal wall and infiltrated the adjacent mesentery, commonly extending to the regional lymph nodes, and sometimes displaying extensive dissemination in the peritoneum. In one case Webster (1966) found involvement of the pleural cavity as observed in two of our cases and occasionally by Cordes \& Shortridge. In Webster's material as in ours and in the series of Cordes $\&$ Shortridge the main mode of spread was lymphogenous, although he observed haematogenous metastases more often than we did, or in three of 63 cases as compared with one of 72 cases in our series. The only case with haematogenous metastasis in our material showed histologically the most predominant glandular organization and there was no peritoneal involvement. This differs from the findings of Dodd, who usually found metastatic nodules in the liver in those cases with most extensive peritoneal dissemination. This is more in accordance with the spread of small intestinal carcinoma in man, where liver metastases are often encountered (Wood). The macroscopic appearance of the site of the primary tumour in our cases is similar to the findings of Webster (1966) and resembles the linitis plastica type of gastric carcinoma in humans. This form of growth is according to Evans (1966) not unusual in small intestinal carcinoma of man. Dodd on the other hand describes the tumour as a cauliflowerlike mass.

The histological features of the tumour in our series are similar to those described by Dodd with solid anaplastic tumours predominating and with an intense desmoplastic reaction in the peritoneal deposits. In man this form is unusual, glandular and papillary patterns being most frequent with occasional frankly mucoid carcinomas (Evans 1966 and Wood).

The admixture of scattered argentaffin cells in the seven tumours in our series that were specially stained is not unexpected. Similar findings have been reported in tumours of the gastrointestinal tract in man (Azzopardi \& Pollock 1963). We found, as these authors did, argentaffin cells in lymph node metastases, which supports the opinion that they represent special differentiation of the tumour cells. 
According to our findings the tumour probably arises deep in the mucosa growing mainly endophytically, penetrating through the bowel wall relatively early and extending along the mesentery to the regional lymph nodes. From the lymph nodes a retrograde lymphogenous spread to the bowel wall proximal to the primary tumour apparently occurs, leading occasionally to secondary constrictions of the gut. The sharp distal boundary of the tumour spread is possibly caused by blocking of distal lymphatics by the intense desmoplastic reaction in the tumour infiltrates in serosa and mesentery.

We cannot offer any satisfactory explanation for the unusually high incidence of carcinoma of the small intestine of Icelandic sheep. With the above-mentioned exception from New Zealand and the limited outbreak observed in Australia, carcinoma of the small intestine of sheep appears to be very rare in other countries. This fact might be interpreted as an indication of a genetic predisposition, different sheep management or unusually heavy exposure to some environmental carcinogenic factors.

In Iceland there is only one breed of sheep, brought to the country during the settlement of Iceland a thousand years ago. Very little influx from other breeds has taken place since. This particular breed is only found in Iceland, the Faroe Islands and Greenland. In New Zealand, all cases, except one in a Lincoln sheep, were found in Romney sheep (Dodd, Cordes \& Shortridge). In the limited outbreak in Australia (McDonald \& Leaver), Merino sheep were affected. If a genetic predisposition is proposed it is apparently not limited to one breed of sheep.

Differences in sheep management in various countries, for example the length of time ewes are kept for breeding purposes, could greatly influence the incidence of carcinoma of the small intestine. According to Webster (1966) it is a common practice in New Zealand to cull breeding ewes with worn teeth from the flocks at the age of seven years for slaughtering. In Iceland such culling of breeding ewes is commonly done at about the same age. If breeding ewes were only kept up to the age of four or five years the observed incidence of carcinoma of the small intestine would fall sharply.

The possibility of unusually high exposure of Icelandic sheep to carcinogenic factors poses a very difficult question, when one considers the long and steadily increasing list of known carcinogenic substances. We shall only briefly discuss some factors, 
which have either been suggested in this connection or should in our opinion be considered.

Webster (1966) discusses the possibility that ultrafine particle phenothiazine used as a worm drench in sheep might be the causal agent in New Zealand. This opinion is based on the circumstantial evidence that phenothiazine is an aromatic amine, and the incidence of carcinoma of the small intestine rose a few years after its introduction as a worm drench in New Zealand. Phenothiazine was also widely used as a worm drench in Iceland up to 1965 , when it was generally replaced by other antihelminthics. If phenothiazine has played a major role in the observed high incidence of carcinoma of the small intestine of sheep in Iceland, the incidence will be expected to decline significantly in the next few years.

Another possible aetiological factor to be considered in Iceland is herring meal, which has been widely used for a long time as a food concentrate for sheep. In 1964 Koppang described toxic liver injury in ruminants in Norway following feeding with herring meal. The toxic substances proved to be nitrosamines, mainly dimethylnitrosamine (Ender et al. 1964), a well known carcinogenic substance. Dimethylnitrosamine was formed during the processing of meal from herring preserved with sodium nitrite. A toxic liver affection of sheep has once been observed in Iceland, and analysis of Icelandic herring meal used as a food concentrate in this instance showed a relatively high nitrosamine content (Gislason 1965, unpublished). In feeding experiments with cattle and/or sheep with herring meal (Koppang, Koppang et al. 1964) and dimethylnitrosamine (Sakshaug et al. 1965) or both (Pálsson \& Dagbjartsson 1968, unpublished) tumours have not been observed. But these were short-term experiments lasting several months only, designed to detect toxic hepatic changes. Long-term experiments would be necessary to clarify the role of dimethylnitrosamine in the evolution of carcinoma of the small intestine of sheep.

By coincidence this factor was eliminated at approximately the same time as phenothiazine. In 1966 new regulations for preservation of herring were introduced in Iceland, which led to reduction of nitrite and nitrosamine contents of herring meal to non-detectable levels (Dagbjartsson 1968, unpublished). Further follow-up surveys are planned in the near future. If these two above-mentioned factors have been of major significance in the 
aetiology of small intestinal carcinoma, a distinct decrease in the incidence is to be expected.

Bracken fern (Pteris aquilina) which contains a potent carcinogen for many animal species (Evans 1968) can be excluded in this connection, as this plant does not grow in Iceland (Einarsson, personal communication).

Even if we accept the possibility of a heavy exposure of Icelandic sheep to carcinogenic substances in the fodder, the almost exclusive localization of the tumours in the small intestine remains to be explained. Carcinoma in other parts of the gastrointestinal tract was neither found by us nor Webster (1966) in his survey. Admittedly, as main attention was paid to the small intestine in our survey, tumours of other parts of the gastrointestinal tract except those of the large intestine may possibly have escaped our notice. But this observation is consistent with our experience with material received for diagnostic purposes, where tumours of colon as well as other parts of the gastro-intestinal tract are exceedingly rare. This is in accord with reports from other countries. The only exception is from South-Africa, where Schütte (1968) found in a flock of sheep about $8 \%$ incidence of oesophageal tumours during a 10 year period, apparently related to the use of a drench for internal parasites containing a mixture of nicotine solution and copper sulphate. Histological examination of the oesophageal tumours was, however, never carried out to determine their exact nature.

The distribution of gastro-intestinal tumours found in our survey differs markedly from the distribution of gastro-intestinal tumours in humans. According to various reports carcinoma of the small intestine in humans are only $1-5 \%$ of all tumours of the gastro-intestinal tract (McPeak). No satisfactory explanation has been found for the rarity of carcinoma of the small intestine in humans, although some suggestions have been made.

Recently Burkitt (1971) has suggested the possibility, based on the epidemiology of carcinoma of the large intestine in man, that high incidence is associated with low-residue diet, which affects the transit time, bulk, consistency of stool and the bacterial flora of the bowel. Burkitt argues that the rarity of epithelial tumours in the small intestine in humans supports his hypothesis. The generally reported rarity of bowel tumours of domestic ruminants fed a high-residue diet supports this opinion, but leaves the observed high incidence of small intestinal carcino- 
ma of Icelandic sheep a still greater puzzle. A further study of this affection of sheep should be rewarding, especially from the viewpoint of comparative pathology.

\section{ACKNOWLEDGEMENTS}

We wish to thank Dr. G. Pétursson, Dr. P. A. Pálsson, Dr. S. Sigurdarson and Dr. Th. Thorgeirsson for many helpful suggestions, Mrs. E. Benediktsdóttir and Mr. P. Sigurdsson for technical assistance.

\section{REFERENCES}

Azzopardi, J. G. \& D. J. Pollock: Argentaffin and argyrophil cells in gastric carcinoma. J. Path. Bact. 1963, 86, 443-451.

Burkitt, D. P.: Epidemiology of cancer of the colon and rectum. Cancer (Philad.) 1971, 28, 3-13.

Cordes, D. O.\& E. H. Shortridge: Neoplasms of sheep: a survey of 256 cases recorded at Ruakura Animal Health Laboratory. N. Z. vet. J. $1971,19,55-64$.

Cotchin, E.: Neoplasms of the domesticated mammals. Review Series No. 4 of the Commonwealth Bureau of Animal Health, Commonwealth Agricultural Bureaux, Farnham Royal, Bucks., England 1956.

Dodd, D. C.: Adenocarcinoma of the small intestine of sheep. N. Z. vet. J. 1960, 8, 109-112.

Ender, F., G. Havre, A. Helgebostad, N. Koppang, R. Madsen \& L. Ceh: Isolation and identification of hepatotoxic factor in herring meal produced from sodium nitrite preserved herring. Naturwissenschaften 1964, 51, 637-638.

Evans, I. A.: The radiomimetic nature of bracken toxin. Cancer Res. $1968,28,2252-2261$.

Evans, R. W.: Histological Appearances of Tumours. E. \& S. Livingstone, Edinburgh and London 1966.

Koppang, N.: An outbreak of toxic liver injury in ruminants. Case reports pathological-anatomical investigations, and feeding experiments. Nord. Vet.-Med. 1964, 16, 305-322.

Koppang, N., P. Slagsvold, M. A. Hansen, E. Sögnen \& R. Svenkerud: Feeding experiments with meal produced from herring preserved with sodium nitrite and formalin. Nord. Vet.-Med. 1964, 16, $343-362$.

McDonald, J. W. \& D.D. Leaver: Adenocarcinoma of the small intestine of merino sheep. Aust. vet. J. 1965, 41, 269-271.

McPeak, C. J.: Malignant tumors of the small intestine. Amer. J. Surg. $1967,114,402-411$. 
Monlux, A. W., W. A. Anderson \& C. L. Davis: A survey of tumors occurring in cattle, sheep and swine. Amer. J. vet. Res. 1956, 17, 646 -677.

Moulton, J. E.: Tumors in Domestic Animals. Univ. California Press, Berkeley and Los Angeles 1961.

Pearse, A. G. E.: Histochemisiry. Vol. I. Churchill, London 1968.

Sakshaug, J., E. Sögnen, M. A. Hansen \& N. Koppang: Dimethylnitrosamine, its hepatotoxic effect in sheep and its occurrence in toxic batches of herring meal. Nature (Lond.) 1965, 206, 1261-1262.

Schütte, K. H.: Esophageal tumors in sheep: some ecological observations. J. nat. Cancer Inst. 1968, 41, 821-824.

Webster, W. M.: Neoplasia in food animals with a special reference to the high incidence in sheep. N. Z. vet. J. 1966, 14, 203-214.

Webster, W. M.: A further survey of neoplasms in abattoir sheep. N.Z. vet. J. $1967,15,51-54$.

Wood, D. A.: Tumors of the small intestines. Atlas of Tumor Pathology, Armed Forces Institute of Pathology, Washington D.C. 1967.

\section{SAMMENDRAG}

Carcinom i tyndtarmen hos får i Island. En patologisk og epizootiologisk undersøgelse.

En usædvanlig høj incidens, d.v.s. $0.97 \%$, af carcinom i tyndtarmen observeret hos islandske får rapporteres. Svulsterne var lokaliserede til jejunum og den $\emptyset$ verste del af ileum. Den makroskopiske og mikroskopiske patologi beskrives og sammenlignes med carcinom i tyndtarmen hos andre husdyr og mennesker.

Etiologiske faktorer diskuteres og den mulighed drøftes, at fårene er blevet udsat for carcinogene substanser, især nitrosaminer i kraftfoder.

Disse fund diskuteres med henblik på nugældende ideer om carcinogenese i tarmen.

(Received September 18, 1972).

Reprints may be requsted from: Gudmundur Georgsson, Institute for Experimental Pathology, University of Iceland, Keldur, Reykjavik, Iceland.

\section{ADDENDUM}

Since this manuscript was submitted for publication, Simpson (Simpson, B. H.: An epidemiological study of carcinoma of the small intestine in New Zealand sheep. N. Z. vet. J. 1972, 20, 91-97) has published evidence that seems to exclude phenothiazine as of major significance in the aetiology of small intestinal carcinoma of sheep in New Zealand. 